\title{
Habitat-use model for the New Zealand endemic frog Leiopelma hochstetteri
}

\author{
Eduardo Nájera-Hillman ${ }^{1, *}$, Andrea C. Alfaro ${ }^{1}$, Steve O'Shea ${ }^{2}$, Barbara Breen ${ }^{1}$, \\ Nick Garret ${ }^{3}$, Peter King ${ }^{4}$ \\ ${ }^{1}$ School of Applied Sciences, ${ }^{2}$ Earth and Oceanic Sciences Research Institute, and ${ }^{3}$ Faculty of Health and Environmental
Sciences, Auckland University of Technology, Auckland 1142, Private Bag 92006, New Zealand
${ }^{4}$ La Trobe Mainland Island Restoration Project, 10 La Trobe Track, Karekare, RD 2, New Lynn, Auckland, New Zealand
}

ABSTRACT: Leiopelma hochstetteri is the most widespread and abundant endemic frog species in New Zealand, although it now survives only in spatially fragmented populations throughout the North Island of New Zealand and the Great Barrier Island of northeastern New Zealand. The species is known to occur in wet areas adjacent to shaded streams in forested catchments; however, no quantitative ecological data exist to enable characterisation of its habitat. In the present study, novel data on the current distribution and habitat requirements of this species are reported for 1 population in the Waitakere Ranges, northwestern New Zealand, which is considered as a conservation management unit for the species. Frogs were found within most streams surveyed (68.2\%). Statistical modelling demonstrates that frogs most likely occur in small, erosive streams with coarse substrates and cold waters, surrounded by mature or undisturbed riparian vegetation. Anthropogenic activities such as clearing or logging are identified as threats to this frog species.

KEY WORDS: Amphibian distribution $\cdot$ Habitat $\cdot$ Endemic $\cdot$ Detection probability $\cdot$ Occupancy

\section{INTRODUCTION}

Understanding the links between amphibian distribution and habitat structure is an important first step in addressing the current global decline in amphibian populations (Cushman 2006, Hamer \& McDonnell 2008), partly because the identification of ideal habitat characteristics may facilitate the identification of important areas for the conservation of endangered or vulnerable species. Populations of endemic island amphibians are particularly vulnerable to environmental change and are susceptible to population declines (Lecis \& Norris 2004, Moore et al. 2004) because of their restricted distribution ranges.

Endemic New Zealand frogs (Leiopelma hochstetteri, L. archeyi, L. hamiltoni and L. pakeka) are among the most primitive living frogs in the world (Ford \& Cannatella 1993, Roelants \& Bossuyt 2005). Subfossil remains indicate that the genus Leiopelma was once widely distributed throughout the New Zealand archi- pelago, but several species have become extinct since human colonisation began (Worthy 1987). A number of biological features render these frogs vulnerable to population decline or extinction. These native species have restricted distribution ranges, appear to be long lived, and have low reproductive rates (Wells 2007).

Leiopelma hochstetteri is currently the most widespread and abundant New Zealand native frog species. It is ranked no. 38 on the Zoological Society of London's amphibian EDGE list of the most evolutionarily distinct and globally endangered amphibians of the world, is recognized as 'Vulnerable' in the IUCN (International Union for Conservation of Nature) Red List of threatened species, and is fully protected by New Zealand legislation. It is the most aquatic of native frog species in New Zealand and now survives in spatially fragmented populations across the northern half of the North Island, and on the Great Barrier Island (Baber et al. 2006). Substantial genetic variation among frogs from different areas of its current distrib- 
ution suggests that each population should be considered a distinct unit worthy of separate conservation (Green 1994, Gemmell et al. 2003, Fouquet et al. 2009).

The Waitakere Ranges are considered a Leiopelma hochstetteri conservation management unit (CMU; Green 1994, Fouquet et al. 2009). This area consists of a series of hills that run roughly north to south, and contain several streams, a few lakes and some humanmade water reservoirs. The vegetation cover in this area reflects the impact of timber milling, burning and farming (Esler 2006)-milling and burning of the native forest occurred prior to the 1930 s. Today, $60 \%$ of the Waitakere Ranges falls within a Regional Park and is afforded protection to minimise the effects of development on the region, although much of the land surrounding the park is privately owned; of this land, $78 \%$ is still covered with native forest (ARC 2003). Since April 2008, the Waitakere Ranges Heritage Area Act has promoted the protection and enhancement of the terrestrial and aquatic ecosystems within the park, in addition to the residential areas.

The abundance and distribution of Leiopelma hochstetteri in the Waitakere Ranges have been surveyed (Ziegler 1999, Bradfield 2005) and its habitat has been described as wet, alongside shaded streams and seepages (McLennan 1985, Bell et al. 2004), where the species' abundance is positively associated with the amount of coarse substrates in the stream channel (Nájera-Hillman et al. 2009a). However, the links between $L$. hochstetteri distribution and its habitat characteristics have not been quantitatively investigated.

Potential agents of decline of Leiopelma hochstetteri include habitat loss and modification, predation by introduced mammals (e.g. ship rats) and disease (Towns \& Daugherty 1994, Baber et al. 2006, Bishop et al. 2009). However, Nájera-Hillman et al. (2009a) did not find conclusive evidence that ship rats are a threat, and, despite extensive surveys, the amphibian disease caused by the fungus Batrachochytrium dendrobatidis has not been detected in L. hochstetteri (Bishop et al. 2009).

As in all other organisms, the distribution of amphibians is strongly determined by variability in habitat characteristics (Hutchinson 1957). Amphibian-habitat relationships can be described using statistical models that relate species distribution, richness, diversity and/or abundance to a range of factors, such as topography and vegetation (Cushman 2006). Binary logistic regression is a particularly useful technique for determining the habitat variables that best explain species distribution over different spatial scales (Lecis \& Norris 2004). However, a species may remain undetected in a survey of a sampling unit even when it is present (MacKenzie et al. 2002), particularly if the species is cryptic, with the result that its true distribution is underestimated (MacKenzie \& Royle 2005). Unaccounted detection probability of a species could influence habitat-use models, causing biased estimates of habitat effects or misleading inferences about the 'conservation value' of different habitats (Tyre et al. 2003, $\mathrm{Gu} \&$ Swihart 2004). However, if sampling units are repeatedly surveyed within a relatively short time frame, some methods that incorporate estimates of detection probabilities can be used to provide reliable distribution estimates (e.g. MacKenzie et al. 2002, Royle \& Nichols 2003). Moreover, the models of MacKenzie et al. (2002) can be used to investigate the influence of environmental characteristics on L. hochstetteri detection probability and occurrence (Crossland et al. 2005), and are therefore likely to provide reliable information about habitat use of different populations of the species.

We present results of Leiopelma hochstetteri monitoring in the Waitakere Ranges that enabled statistical modelling of the species' occupancy, detection probability and habitat use. This information is likely to provide basic ecological data to facilitate appropriate conservation management of this endemic, rangerestricted and threatened species. The aims of this research are thus to (1) establish a reliable estimate of frog occupancy in the Waitakere Ranges, and (2) identify associations between frog occupancy and habitat characteristics.

\section{MATERIALS AND METHODS}

Study sites. Field work was conducted in the Waitakere Ranges, Auckland, New Zealand (36 53' to $37^{\circ} 03^{\prime} \mathrm{S}, 174^{\circ} 27^{\prime}$ to $174^{\circ} 34^{\prime} \mathrm{E}$ ), at 16 to $300 \mathrm{~m}$ elevation. To assess the proportion of sites occupied (occupancy) and the detection probability of Leiopelma hochstetteri, 22 sites were randomly selected throughout the study area with the aid of a 1:50000 topographic map. Sites were composed of stream sections, which are defined as the stream reach between 2 consecutive stream junctions. Site selection resulted in stream sections of variable length and hierarchy (first, second and third order streams according to the Strahler [1957] classification system) (Fig. 1). No preexisting knowledge regarding frog presence/absence was used in site selection.

Frog surveys. Frog searches were conducted within each selected stream section and were undertaken in accordance with established New Zealand survey protocols (Bradfield 2005, Crossland et al. 2005, Baber et al. 2006). Each stream section was searched thoroughly by investigators moving upstream from a starting point, while carefully examining all available refu- 


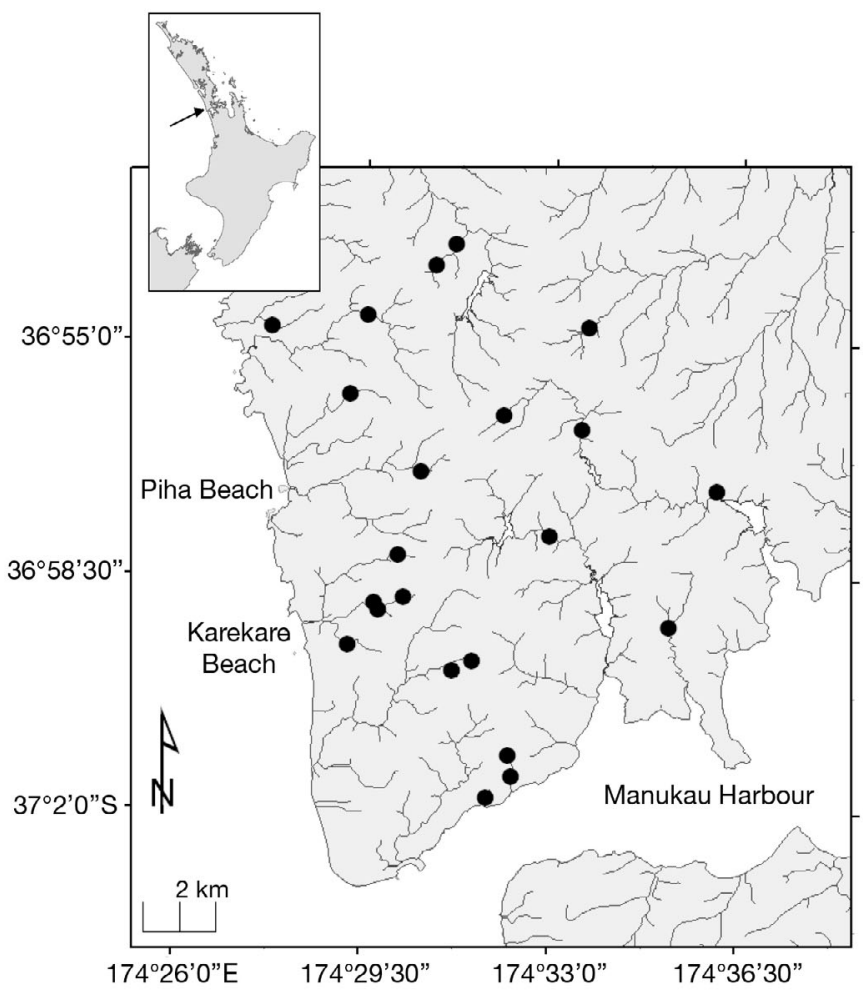

Fig. 1. Location of study sites (๑). Small map: North Island, New Zealand; (arrow) Waitakere Ranges

gia for frogs (underneath rocks, logs and leaves, and inside crevices and tunnels). All objects that had to be moved were carefully restored to their original position to minimise habitat disturbance. Both sides of the stream along each stream section were searched from the water's edge to the stream bank.

To establish frog occupancy and detection probability, we followed the recommendations of MacKenzie \& Royle (2005). Five searches were conducted at each stream section during late spring 2007 and summer 2008. Repeated searches in stream sections were conducted as multiple discrete visits (i.e. on different days) using multiple observers. The observers searched within the stream section until 1 frog was found or until the section had been searched completely. In addition, survey bias was reduced by rotating sites among observers on any given day. All observers had previously been trained for the surveys by experienced frog searchers.

Environmental characterisation. Detailed descriptions of the riparian tree community structure and stream section geomorphic characteristics were made; measurements of water chemistry and observations of weather conditions were undertaken at all sites. Stream section geomorphic characteristics were obtained from the New Zealand River Environment Classification (MfE 2004) and confirmed by in situ observations. These included stream hierarchy, geol- ogy, hydraulic process (erosive or depositional) and upstream catchment area. Silt in stream water was visually assessed by recording the presence of suspended fine sediments in stream water and/or by the incidence of accumulated fine sediments between coarse substrates (boulders and cobbles).

Species, density and diameter at breast height (DBH) of all riparian trees $(\geq 3 \mathrm{~cm} \mathrm{DBH})$, were recorded in 6 belt transects (10 $\mathrm{m}$ long, $4 \mathrm{~m}$ wide) at each stream section during the winter of 2007 . Transects were oriented perpendicular to the stream channel, with the starting point being located at the edge of the stream.

Water chemistry and weather conditions were recorded in situ on the day frog searches were conducted. Water temperature, $\mathrm{pH}$, dissolved oxygen concentration, and conductivity were measured using a water measurement pocket meter (WTW MultiLine P4). Weather conditions, such as air temperature and relative humidity, were recorded using a handheld weather system (Skywatch GEOS No.11).

Data analyses. The approach of MacKenzie et al. (2002) that was implemented in the program PRESENCE was used to estimate the detection probability and occupancy of Leiopelma hochstetteri. This model assumes that the distribution of the frog within a season is 'closed' (i.e. there are neither colonisations nor extinctions). Thus, we restricted frog surveys to a single season, and all 5 visits to a single site were completed within $15 \mathrm{~d}$. To estimate occupancy, we assumed detection probability to be constant across surveys and also to be survey specific.

Estimates of detection probabilities can be used to assess, with a specific degree of confidence, the number of visits necessary to determine whether a species is truly absent from a site (Kéry 2002). We used the approach of Pellet \& Schmidt (2005) to calculate the minimum number of visits necessary to be $95 \%$ certain that Leiopelma hochstetteri would be absent from a stream section in the Waitakere Ranges.

The association between the occupancy and detection probability of Leiopelma hochstetteri and habitat characteristics obtained from the environmental data was modelled using an information-theoretic approach, which allows one to select a 'best' model and to rank the remaining models (Burnham \& Anderson 2002). Site-specific variables (e.g. stream hierarchy and catchment area) were used to model frog occupancy, and sampling occasion variables (e.g. water temperature and $\mathrm{pH}$ ) were used to model frog detection probability. However, the average values of the sampling occasion variables per site were also used as site variables. Akaike's information criterion (AIC) was used to compare models with different environmental variables; the lowest values of this criterion are associated with models that more thoroughly explain the variation in 
the frog detection data without introducing the imprecision generated by the inclusion of additional parameters (Sherman \& Runge 2002). However, due to the relatively low number of surveyed sites, we adjusted the AIC for small sample size $\left(\mathrm{AIC}_{\mathrm{C}}\right)$ in the model selection process (Burnham \& Anderson 2002). Using the program PRESENCE, we compared the $\mathrm{AIC}_{\mathrm{c}}$ values of each of the measured environmental variables alone, and we then combined the variables with the highest values to see if the combination produced a 'post hoc' model that better fits the data than the best single-variable model alone. $\mathrm{AIC}_{\mathrm{C}}$ differences $\left(\Delta \mathrm{AIC}_{\mathrm{C}}=\mathrm{AIC}_{\mathrm{C}}-\mathrm{min}\right.$ $\mathrm{AIC}_{\mathrm{c}}$ ) were used to define the level of empirical support for the models that satisfactorily explained the occupancy and detection probability of L. hochstetteri ( $0-3$ : substantial support, 3.1-9: considerably less support, and >10: no support) (Johnson \& Omland 2004, Hasui et al. 2007, Crawford \& Semlitsch 2008).

Additionally, we calculated Akaike weights $\left(w_{\mathrm{i}}\right)$ to determine the weight of evidence in favour of each 'post hoc' model. Lastly, we judged the strength of the best model by verifying that the error estimates $(\beta)$ of the untransformed coefficients for each of the environmental variables included in the mod-

els did not encompass zero.

\section{RESULTS}

\section{Frog occupancy and detection probability}

Leiopelma hochstetteri was detected in 15 of 22 sites. Thus, the average occupancy (naive estimate) was $68.18 \%$. After accounting for detection probability in the program PRESENCE, the estimated occupancy was $0.68 \pm$ $0.09 \mathrm{SE}$ when detection probability was considered to be either constant or survey specific. Parity between the average and estimated occupancy was not surprising, given the high average detection probability $(0.88 \pm 0.04)$ of $L$. hochstetteri in this study.

Based on the average detection probability (0.88), the total number of sites surveyed (22) and the number of frog searches per site (5), the minimum number of searches necessary to be $95 \%$ certain that Leiopelma hochstetteri would be absent from a stream section was 1.4, indicating that 2 searches would suffice for this purpose.

\section{Relationship between frog distribution and environmental characteristics}

The habitat characteristics of the sites that were occupied and those that were not occupied by Leiopelma hochstetteri are summarised in Table 1. Frogs were detected primarily within first-order streams within small catchment areas located in high-altitude regions; frogs were also more commonly found in nonsilted streams. Sites where frogs were present tended to have colder water, as well as colder air temperatures and higher relative humidity.

Riparian vegetation characteristics (e.g. mean tree diameter, tree density) were similar in occupied and unoccupied sites (Table 1). Although the structure of the riparian tree community was similar between unoccupied and occupied sites, with the most abundant tree species being the tree ferns Dicksonia squarrosa and Cyathea dealbata, kanuka trees Kunzea ericoides were more abundant at sites that were not occupied by frogs, while nikau palms Rhopalostylis sapida, tawa trees Beilschmiedia tawa and kahikatea trees Dacrycarpus dacrydioides were more abundant at occupied sites (Fig. 2).

Table 1. Habitat characteristics of sites surveyed for Leiopelma hochstetteri presence. DBH: diameter at breast height

\begin{tabular}{|c|c|c|c|c|}
\hline \multirow[t]{2}{*}{ Characteristic } & \multicolumn{2}{|c|}{ Unoccupied $(\mathrm{N}=7)$} & \multicolumn{2}{|c|}{ Occupied $(\mathrm{N}=15)$} \\
\hline & Mean & $\mathrm{SE}$ & Mean & $\mathrm{SE}$ \\
\hline \multicolumn{5}{|l|}{ Riparian trees } \\
\hline Mean diameter (cm) & 12.98 & 0.75 & 12.41 & 0.52 \\
\hline $\mathrm{SD}$ of $\mathrm{DBH}$ & 9.57 & 0.96 & 8.57 & 0.55 \\
\hline Density (trees $\mathrm{m}^{-2}$ ) & 2.85 & 0.27 & 2.78 & 0.23 \\
\hline Species richness & 14.43 & 0.78 & 14.00 & 0.70 \\
\hline \multicolumn{5}{|l|}{ Water chemistry } \\
\hline Dissolved oxygen $\left(\mathrm{mg} \mathrm{l}^{-1}\right)$ & 8.22 & 0.64 & 8.67 & 0.16 \\
\hline Temperature $\left({ }^{\circ} \mathrm{C}\right)$ & 16.05 & 0.41 & 14.27 & 0.17 \\
\hline $\mathrm{pH}$ & 7.13 & 0.26 & 7.14 & 0.07 \\
\hline Conductivity $\left(\mu \mathrm{S} \mathrm{cm}^{-1}\right)$ & 190.03 & 33.9 & 189.49 & 4.51 \\
\hline \multicolumn{5}{|l|}{ Atmospheric } \\
\hline Relative humidity (\%) & 61.44 & 4.65 & 64.83 & 0.79 \\
\hline Temperature $\left({ }^{\circ} \mathrm{C}\right)$ & 20.57 & 0.71 & 18.02 & 0.29 \\
\hline \multicolumn{5}{|l|}{ Geomorphic } \\
\hline Catchment area (ha) & 354.30 & 125.3 & 160.15 & 14.6 \\
\hline Altitude (m.a.s.l.) & 137.14 & 23.6 & 195.53 & 4.89 \\
\hline \multicolumn{5}{|c|}{ Stream hierarchy (no. of sites; \%) } \\
\hline 1st order (9) & \multicolumn{2}{|c|}{22.2} & \multicolumn{2}{|c|}{77.8} \\
\hline 2nd order (8) & \multicolumn{2}{|c|}{37.5} & \multicolumn{2}{|c|}{62.5} \\
\hline 3rd order(5) & \multicolumn{2}{|c|}{40.0} & \multicolumn{2}{|c|}{60.0} \\
\hline \multicolumn{5}{|l|}{ Geology (no. of sites; \%) } \\
\hline Volcanic acidic (18) & \multicolumn{2}{|c|}{33.3} & \multicolumn{2}{|c|}{66.7} \\
\hline Soft sedimentary (4) & \multicolumn{2}{|c|}{25.0} & \multicolumn{2}{|c|}{75.0} \\
\hline \multicolumn{5}{|c|}{ Hydraulic process (no. of sites; \%) } \\
\hline Erosive (17) & \multicolumn{2}{|c|}{29.4} & \multicolumn{2}{|c|}{70.6} \\
\hline Depositional (5) & \multicolumn{2}{|c|}{40.0} & \multicolumn{2}{|c|}{60.0} \\
\hline \multicolumn{5}{|l|}{ Water clarity (no. of sites; \%) } \\
\hline Silted (5) & \multicolumn{2}{|c|}{80.0} & \multicolumn{2}{|c|}{20.0} \\
\hline Clear (17) & \multicolumn{2}{|c|}{17.6} & \multicolumn{2}{|c|}{82.4} \\
\hline
\end{tabular}




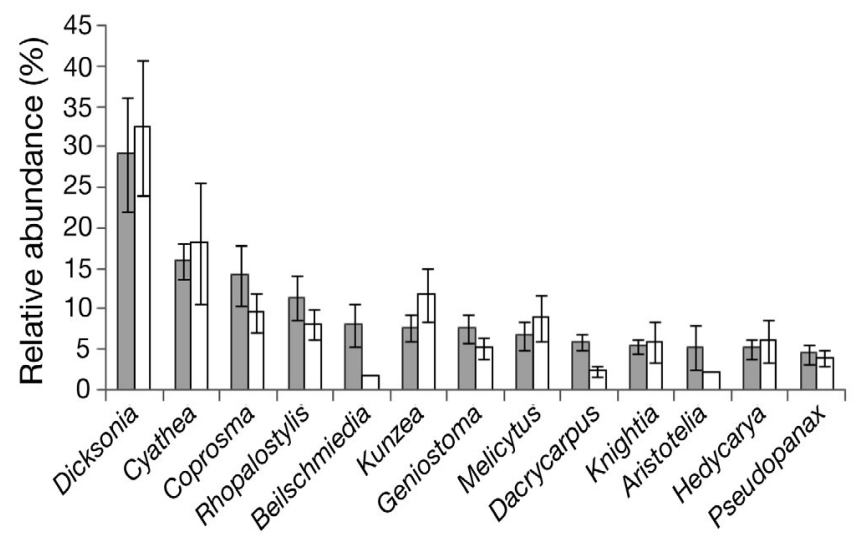

Fig. 2. Relative abundance (mean $\pm \mathrm{SE}$ ) of dominant riparian trees (genera) at the study sites. Grey bars: sites occupied by

frogs; white bars: sites not occupied by frogs; $N=132$
Of the 22 variables measured during this study, only 6 were substantially associated with Leiopelma hochstetteri occurrence $\left(\Delta \mathrm{AIC}_{\mathrm{c}}<3\right)$. Of these, water temperature best predicted the occurrence of L. hochstetteri, followed by air temperature and catchment area. The categorical variables erosive hydraulic process, firstorder streams and volcanic acidic geology were also substantially associated with frog occurrence; however, these models did not present a better fit than the null model $[\Psi(),. p($.$) ; Table 2]. All the models that con-$ sidered the effect of survey-specific variables (i.e. detection probability models) presented very low levels of support $\left(\Delta \mathrm{AIC}_{\mathrm{C}}>10\right)$ to explain frog detectability (Table 2). Therefore, the multiple variable models ('post hoc' models) developed subsequently only included combinations of the 6 most important sitespecific variables (Table 3). Of the multiple variable

Table 2. Summary of $\mathrm{AIC}_{\mathrm{c}}$ (corrected Akaike's information criterion) model selection for single-variable models of stream occupancy by Leiopelma hochstetteri, Waitakere Ranges, New Zealand. The symbols $\Psi$ and $p$ indicate the occupancy and the detection portions of the models, respectively. Values of $\Psi$ and $p$ are untransformed estimates. $\Delta \mathrm{AIC}_{\mathrm{c}}$ : $\mathrm{AIC}_{\mathrm{c}}-\mathrm{min}_{\mathrm{AIC}}$. +++ : substantial support + +/-: considerably less support; -: no support; (.): null model; Srvy: survey

\begin{tabular}{|c|c|c|c|c|c|}
\hline Model & $\mathrm{AIC}_{\mathrm{c}}$ & $\Delta \mathrm{AIC}_{\mathrm{c}}$ & $\begin{array}{l}\text { Level of support } \\
\text { for model }\end{array}$ & $\Psi(\mathrm{SE})$ & $p(\mathrm{SE})$ \\
\hline$\Psi($ Water temperature $), p()$. & 85.17 & 0.00 & +++ & $-1.12(0.57)$ & $1.99(0.35)$ \\
\hline$\Psi($ Air temperature $), p()$. & 85.86 & 0.69 & +++ & $-1.05(0.59)$ & $1.99(0.35)$ \\
\hline$\Psi($ Catchment area $), p()$. & 87.09 & 1.92 & +++ & $-0.96(0.66)$ & $1.99(0.35)$ \\
\hline$\Psi(),. p(.)^{\mathrm{a}}$ & 87.19 & 2.02 & +++ & $0.68(0.09)$ & $0.88(0.04)$ \\
\hline$\Psi$ (Erosive), $p()$. & 87.20 & 2.03 & +++ & $0.87(0.53)$ & $1.99(0.35)$ \\
\hline$\Psi(1$ st order $), p()$. & 87.22 & 2.05 & +++ & $1.25(0.80)$ & $1.99(0.35)$ \\
\hline$\Psi($ Volcanic acidic $), p()$. & 88.13 & 2.96 & +++ & $0.69(0.50)$ & $1.99(0.35)$ \\
\hline$\Psi($ Silted), $p()$. & 88.24 & 3.07 & $+/-$ & $-1.39(1.12)$ & $1.99(0.35)$ \\
\hline$\Psi$ (Air relative humidity), $p()$. & 88.85 & 3.68 & $+/-$ & $0.51(0.46)$ & $1.99(0.35)$ \\
\hline$\Psi($ Soft sedimentary), $p()$. & 89.12 & 3.95 & $+/-$ & $1.10(1.15)$ & $1.99(0.35)$ \\
\hline$\Psi(\mathrm{SD}$ of $\mathrm{DBH}), p()$. & 89.37 & 4.20 & $+/-$ & $-0.40(0.47)$ & $1.99(0.35)$ \\
\hline$\Psi(2$ nd order $), p()$. & 89.66 & 4.49 & $+/-$ & $0.51(0.73)$ & $1.99(0.35)$ \\
\hline$\Psi($ Tree evenness $), p()$. & 89.79 & 4.62 & $+/-$ & $0.27(0.45)$ & $1.99(0.35)$ \\
\hline$\Psi($ Dissolved oxygen $), p()$. & 89.79 & 4.62 & $+/-$ & $0.27(0.44)$ & $1.99(0.35)$ \\
\hline$\Psi($ Mean tree diameter), $p()$. & 89.84 & 4.67 & $+/-$ & $-0.25(0.44)$ & $1.99(0.35)$ \\
\hline$\Psi(3 \mathrm{rd}$ order $), p()$. & 89.97 & 4.80 & $+/-$ & $0.40(0.91)$ & $1.99(0.35)$ \\
\hline$\Psi($ Depositional $), p()$. & 89.97 & 4.80 & $+/-$ & $0.40(0.91)$ & $1.99(0.35)$ \\
\hline$\Psi($ Tree species richness), $p()$. & 90.05 & 4.88 & $+/-$ & $-0.15(0.44)$ & $1.99(0.35)$ \\
\hline$\Psi($ Tree diversity), $p()$. & 90.11 & 4.94 & $+/-$ & $0.10(0.43)$ & $1.99(0.35)$ \\
\hline$\Psi($ Tree density $), p()$. & 90.14 & 4.97 & $+/-$ & $-0.07(0.43)$ & $1.99(0.35)$ \\
\hline$\Psi($ Altitude $), p()$. & 90.14 & 4.97 & $+/-$ & $-0.07(0.44)$ & $1.99(0.35)$ \\
\hline$\Psi(\mathrm{pH}), p()$. & 90.17 & 5.00 & $+/-$ & $0.01(0.43)$ & $1.99(0.35)$ \\
\hline$\Psi($ Conductivity $), p()$. & 90.17 & 5.00 & $+/-$ & $0.02(0.41)$ & $1.99(0.35)$ \\
\hline \multirow[t]{5}{*}{$\Psi()$, Survey-specific $p^{\text {a }}$} & 95.47 & 5.33 & $+/-$ & $0.68(0.09)$ & Srvy 10.87 (0.09) \\
\hline & & & & & Srvy $21.00(0.00)$ \\
\hline & & & & & Srvy $30.87(0.09)$ \\
\hline & & & & & Srvy $40.80(0.10)$ \\
\hline & & & & & Srvy $50.87(0.09)$ \\
\hline$\Psi(),. p($ Water temperature) & 120.21 & 35.04 & - & $1.23(0.64)$ & $-1.01(0.29)$ \\
\hline$\Psi(),$.$p (Air temperature)$ & 125.33 & 40.16 & - & $1.08(0.57)$ & $-0.79(0.27)$ \\
\hline$\Psi(),. p(\mathrm{pH})$ & 132.87 & 47.70 & - & $0.88(0.50)$ & $-0.37(0.25)$ \\
\hline$\Psi(),$.$p (Relative humidity)$ & 133.76 & 48.59 & - & $0.88(0.50)$ & $0.33(0.28)$ \\
\hline$\Psi(),$.$p (Dissolved oxygen)$ & 133.94 & 48.77 & - & $0.89(0.50)$ & $0.28(0.25)$ \\
\hline$\Psi(),. p($ Conductivity) & 134.73 & 49.56 & - & $0.89(0.50)$ & $0.27(0.39)$ \\
\hline
\end{tabular}


Table 3. Summary of $\mathrm{AIC}_{\mathrm{c}}$ (corrected Akaike's information criterion) model selection for 'post hoc' models of stream occupancy by Leiopelma hochstetteri, Waitakere Ranges, New Zealand. The global model includes all variables with substantial association with frog occurrence. The symbols $\Psi$ and $p$ indicate the occupancy and the detection portions of the models, respectively. $\Delta \mathrm{AIC}_{\mathrm{c}}$ : $\mathrm{AIC}_{\mathrm{C}}-\min \mathrm{AIC}_{\mathrm{C}}, \mathrm{K}$ : no. of parameters in the model, $w$ : Akaike weights. (.): null model

\begin{tabular}{|c|c|c|c|c|}
\hline Model & $\mathrm{AIC}_{\mathrm{c}}$ & $\Delta \mathrm{AIC}_{\mathrm{c}}$ & $\mathrm{K}$ & $w$ \\
\hline$\Psi$ (Water temperature, erosive), $p()$. & 84.30 & 0.00 & 3 & 0.31 \\
\hline$\Psi$ (Water temperature), $p(.)^{\mathrm{a}}$ & 85.17 & 0.87 & 2 & 0.14 \\
\hline$\Psi$ (Water temperature, volcanic acidic), $p()$. & 85.49 & 1.19 & 3 & 0.17 \\
\hline$\Psi$ (Water temperature, 1 st order), $p()$. & 86.36 & 2.06 & 3 & 0.11 \\
\hline$\Psi$ (Water temperature, catchment area, erosive), $p()$. & 87.25 & 2.95 & 4 & 0.12 \\
\hline$\Psi$ (Water temperature, catchment area), $p()$. & 87.28 & 2.98 & 3 & 0.07 \\
\hline$\Psi$ (Water temperature, catchment area, volcanic acidic), $p()$. & 88.22 & 3.92 & 4 & 0.07 \\
\hline$\Psi$ (Water temperature, catchment area, 1st order), $p()$. & 89.28 & 4.98 & 4 & 0.04 \\
\hline$\Psi($ Global $), p()$. & 94.44 & 10.14 & 6 & 0.02 \\
\hline aBest model from Table 2 & & & & \\
\hline
\end{tabular}

models, only one presented better fit to the data than the best single-variable model. This model included water temperature and erosive hydraulic process as variables, and was 2.2 times more likely to be the best explanation for frog occurrence compared to the best single-variable model, which included water temperature only, as indicated by the Akaike weights $(0.31 / 0.14$; Table 3$)$. Water temperature was negatively associated with frog occurrence, while erosive hydraulic process was positively associated with it; both variables had a strong association with frog occurrence since their error estimates did not encompass 0 (Tables $2 \& 4$ ).

\section{DISCUSSION}

\section{Frog occupancy and detection probability}

Leiopelma hochstetteri was found within most survey stream sections, and presence/absence data were adequately modelled to provide a reliable estimate of the occupancy of this species. The occupancy in the study area $(0.68 \pm 0.09 \mathrm{SE})$ was higher than that previously reported by Ziegler (1999) and Bradfield (2005)

Table 4. Untransformed variable estimates and SEs for explanatory variables from the best 'post hoc' occupancy model for Leiopelma hochstetteri, Waitakere Ranges, New Zealand

\begin{tabular}{|lc|}
\hline Variable & Estimate (SE) \\
\hline Water temperature & $-1.43(0.76)$ \\
Erosive hydraulic process & $1.16(0.68)$ \\
\hline
\end{tabular}

for the Waitakere Ranges (Table 5). However, these 2 latter studies did not take frog detection probability into consideration (i.e. sites were surveyed only once) in assessing frog distribution, and therefore could not compute SE or CI values for their occupancy measurements. Consequently, it cannot be determined whether differences in occupancy values in these 3 studies are significant. Although similar frog search protocols were used in all 3 studies (i.e. daytime searches of potential refugia), the sampling units surveyed were different; specific length transects (5 to $50 \mathrm{~m}$ ) were used in previous studies (Ziegler 1999, Bradfield 2005), in contrast to entire stream sections in the present study. The smaller sampling unit size, together with the lack of detection probability incorporation, might have led to underestimation of occupancy in previous studies. Therefore, the current study provides, for the first time, a reliable estimate of occupancy for the studied L. hochstetteri population.

Our detection probability estimate $(p=0.88 \pm 0.04)$ indicates that during spring-summer, 2 frog searches on a particular stream section are enough to be $95 \%$ certain that Leiopelma hochstetteri is absent from that stream section, at least within the Waitakere Ranges. Nevertheless, it should be noted that the detection probabilities of some amphibian species (e.g. Ambystoma tigrinum) may vary among years (MacKenzie et al. 2003); consequently, the number of searches neces- 
sary to establish the absence of a given species may need to be redetermined shortly before studies are conducted. Moreover, Crossland et al. (2005) demonstrated that the detection probability of L. hochstetteri may vary ( $p=0.61-0.94)$ among different areas and/or according to the sampling unit utilised (i.e. specific length transects, rock patches within a stream). Therefore, if development of an area where a protected species occurs is proposed, we recommend that the developer be required to provide evidence that the protected species is absent from particular sites, and do so with statistical certainty, as suggested for other frog species (Hyla arborea, Alytes obstetricans, Bufo calamita and Bombina variegata) in other parts of the world (Pellet \& Schmidt 2005).

\section{Relationship between frog distribution and environmental characteristics}

According to the modelling results, Leiopelma hochstetteri occurrence in the Waitakere Ranges is negatively associated with water temperature, air temperature and stream catchment area (Table 2). It was also positively associated with first-order, erosive streams with volcanic acidic geology. According to the New Zealand River Environment Classification (MfE 2004), the channels of erosive streams with volcanic acidic geology tend to be steep and covered by coarse substrates (i.e. boulders and cobbles); steep-sloped stream channels covered by coarse substrates have been found to be positively associated with frog abundance (Nájera-Hillman et al. 2009a), and this study indicates that they are also positively associated with frog distribution. Furthermore, it has been noted that L. hochstetteri is vulnerable to any disturbance that affects substratum stability (Tessier et al. 1991), particularly, severe storms that cause sudden flooding (McLennan 1985); streams with small catchment areas are less susceptible to flooding than those with large catchment areas (Gregory et al. 1991). This trend may explain why frog occurrence was associated with small catchment streams in the present study. However, this hypothesis should be tested in future investigations.

In terms of microclimatic conditions, Leiopelma hochstetteri has been repeatedly regarded as restricted to cool, shaded streams (Robb 1980, Bell et al. 2004). Thus, it is not surprising that our models showed water temperature to be negatively associated with frog occurrence. Streams must be cool and protected from direct sunlight by overhanging vegetation to accommodate this species' narrow temperature tolerance, as noted for the Hamilton Zoo captive population (K. Goddard pers. comm.). In addition, this frog species has high moisture requirements (Cree 1988). Our results show that frog-occupied sites had slightly higher relative humidity than unoccupied sites (64.8 and $61.4 \%$, respectively). One of the primary effects of riparian forests on streams is shading, which induces both low water temperature and high relative humidity (Sugimoto et al. 1997). Moreover, riparian vegetation provides significant input of organic matter to sustain stream food webs where L. hochstetteri occupies an intermediate trophic level (Nájera-Hillman et al. 2009b). Hence, it is likely that any activity that decreases riparian vegetation in catchments where this species occurs may have a detrimental effect on populations.

Sites unoccupied by frogs showed higher abundance of kanuka Kunzea ericoides than occupied sites; this tree species is characteristic of earlier successional stages in New Zealand forests (Payton et al. 1984, Platt 2002). In contrast, occupied sites had greater abundance of nikau palms Rhopalostylis sapida, tawa trees Beilschmiedia tawa and kahikatea trees Dacrycarpus dacrydioides (Fig. 2), which are characteristic species of climax forests (Platt 2002). Thus, we suggest that Leiopelma hochstetteri has greater affinity for streams with mature or undisturbed surrounding forest cover.

\section{Implications for conservation}

Today, Leiopelma hochstetteri is the most widespread endemic New Zealand frog species. However, subfossil remains (10000 to $14000 \mathrm{yr}$ BP) found throughout the North Island and the northern half of the South Island indicate that its range was once greater (Worthy 1987). Moreover, it has been suggested that L. hochstetteri populations may be susceptible to potential agents of decline, such as water pollution, damage to streams and riparian areas by cattle or feral pigs, population fragmentation, and direct habitat destruction (Bell 1994, Green 1994, Whitaker \& Alspach 1999, Baber et al. 2006). Since geographic and genetic subdivisions in $L$. hochstetteri populations indicate that conservation management practice should focus on populations rather than the species as a whole (Green 1994, Fouquet et al. 2009), the methods utilised in the present study could be implemented to identify regional agents of decline for specific $L$. hochstetteri populations, as well as for other rangerestricted populations of amphibians.

Field data collected during this study and the resulting model of frog distribution and habitat use provide a reliable description of the habitat requirements of Leiopelma hochstetteri in the Waitakere Ranges, against which future changes can be assessed. Although the best parsimonious occupancy model only included water temperature and erosive hydraulic pro- 
cess as predictive variables of frog occurrence, the other variables with substantial influence over frog occurrence may also be used to identify adequate areas for $L$. hochstetteri conservation. Thus, ideal stream habitat characteristics for L. hochstetteri in the Waitakere Ranges are identified as first-order, erosive streams covered with coarse substrates, with small catchment areas and mature or undisturbed riparian vegetation. This habitat is well represented in the Waitakere Ranges, as reflected by the high occupancy of $L$. hochstetteri (0.68).

Clearing or logging activities are identified as major threats for Leiopelma hochstetteri. Fortunately, the Waitakere Ranges Regional Park $(60 \%$ of the Waitakere Ranges area) has been protected from clearing or logging of vegetation since the 1940s, and the Waitakere Ranges Heritage Area Act has promoted the protection and enhancement of the terrestrial and aquatic ecosystems within the park, in addition to the residential areas, since April 2008.

In agreement with the notion that stream amphibians demonstrate strong potential as 'sensitive species' (cf. Odum 1992), we conclude that monitoring Leiopelma hochstetteri populations can provide a highly suitable and extremely sensitive barometer for ecological stress derived from vegetation clearing and increased water temperature.

Acknowledgements. We thank E. Beatson, S. Dewas, and P. McBride for field assistance and scientific input; the Auckland Regional Council for permission to undertake the research study at the Waitakere Ranges Regional Park; and the New Zealand Native Frog Recovery Group for valuable scientific inputs. We also thank the National Institute of Water \& Atmospheric Research (NIWA) and the Ministry of the Environment (MfE) for providing data on New Zealand river environment classification. This research was conducted with financial support from the School of Applied Sciences, and the Earth and Oceanic Sciences Research Institute, Auckland University of Technology. This paper is part of the doctoral studies of E.N.-H., who was sponsored by The National Council for Science and Technology, Mexico (scholarship holder no. 205742).

\section{LITERATURE CITED}

ARC (2003) Regional parks management plan, Vol 2. Resource inventory. Auckland Regional Council, Auckland

Baber M, Moulton H, Smuts-Kennedy C, Gemmell N, Crossland M (2006) Discovery and spatial assessment of a Hochstetter's frog (Leiopelma hochstetteri) population found in Maungatautari Scenic Reserve, New Zealand. NZ J Zool 33:147-156

Bell BD (1994) A review of the status of New Zealand Leiopelma species (Anura: Leiopelmatidae), including a summary of demographic studies in coromandel and on Maud Island. NZ J Zool 21:341-349

Bell BD, Carver S, Mitchell NJ, Pledger S (2004) The recent decline of a New Zealand endemic: How and why did populations of Archey's frog Leiopelma archeyi crash over 1996-2001? Biol Conserv 120:189-199

Bishop PJ, Haigh AJM, Marshall LJ, Tocher MD (2009) Consultative draft native frog (Leiopelma species) recovery plan, 2009-2019. Department of Conservation, Wellington

Bradfield KS (2005) A survey for Hochstetter's frog (Leiopelma hochstetteri) in the Waitakere Ranges and Tawharanui Regional Parks, 2004/05. Internal Report Heritage Division, Auckland Regional Council, Auckland

Burnham KP, Anderson DR (2002) Model selection and multimodel inference: an information-theoretic approach. Springer-Verlag, New York

> Crawford JA, Semlitsch RD (2008) Abiotic factors influencing abundance and microhabitat use of stream salamanders in southern Appalachian forests. For Ecol Manag 255: 1841-1847

Cree A (1988) Effects of arginine vasotocin on water balance of three leiopelmatid frogs. Gen Comp Endocrinol 72: $340-350$

Crossland MR, MacKenzie DI, Holzapfel S (2005) Assessment of site-occupancy modeling as a technique to monitor Hochstetter's frog (Leiopelma hochstetteri) populations. Department of Conservation Research \& Development Series 218. Department of Conservation, Wellington

Cushman SA (2006) Effects of habitat loss and fragmentation of amphibians: a review and prospectus. Biol Conserv 128: $231-240$

Esler AE (2006) Forest zones. In: Harvey B, Harvey T (eds) Waitakere Ranges. Waitakere Ranges Protection Society, Auckland, p 67-73

Ford LS, Cannatella DC (1993) The major clades of frogs. Herpetol Monogr 7:94-117

Fouquet A, Green DM, Waldman B, Bowsher JH, McBride KP, Gemmell NJ (2009) Phylogeography of Leiopelma hochstetteri reveals strong genetic structure and suggests new conservation priorities. Conserv Genet doi:10.1007/ s10592-009-9935-8. Available at: www.springerlink.com/ content/4346777gm310m755/

Gemmell NJ, Bowsher JH, Gomas KP (2003) Genetic affinities of Hochstetter's frog (Leiopelma hochstetteri) populations in the Bay of Plenty. Department of Conservation Science Internal Series 141. Department of Conservation, Wellington

Green DM (1994) Genetic and cytogenetic diversity in Hochstetter's frog, Leiopelma hochstetteri, and its importance for conservation management. NZ J Zool 21: 417-424

> Gregory SV, Swanson FJ, McKee WA, Cummins KW (1991) An ecosystem perspective of riparian zones: focus between land and water. Bioscience 41:540-551

$>$ Gu W, Swihart RK (2004) Absent or undetected? Effects of non-detection of species occurrence on wildlife-habitat models. Biol Conserv 116:195-203

> Hamer AJ, McDonnell MJ (2008) Amphibian ecology and conservation in the urbanising world: a review. Biol Conserv 141:2432-2449

> Hasui E, da Mota Gomez VS, Rodrigues WS (2007) Effects of vegetation traits on habitat preferences of frugivorous birds in Atlantic rain forest. Biotropica 39:502-509

Hutchinson GE (1957) A treatise on limnology. Wiley \& Sons, New York

> Johnson JB, Omland KS (2004) Model selection in ecology and evolution. Trends Ecol Evol 19:101-108

> Kéry M (2002) Inferring the absence of a species - a case study of snakes. J Wildl Manag 66:330-338

> Lecis R, Norris K (2004) Habitat correlates of distribution and local population decline of the endemic Sardinian newt Euproctus platycephalus. Biol Conserv 115:303-317 
MacKenzie DI, Royle JA (2005) Designing occupancy studies: general advice and allocating survey effort. J Appl Ecol 42:1105-1114

MacKenzie DI, Nichols JD, Lachman GB, Droege S, Royle AJ, Langtimm CA (2002) Estimating site occupancy rates when detection probabilities are less than one. Ecology 83:2248-2255

MacKenzie DI, Nichols JD, Hines JE, Knutson ME, Franklin AB (2003) Estimating site occupancy, colonization, and local extinction when a species is detected imperfectly. Ecology 84:2200-2207

McLennan JA (1985) Some observations on Hochstetter's frog in the catchment of the Motu river, East Cape. NZ J Ecol $8: 1-4$

MfE (Ministry of the Environment) (2004) New Zealand river environment classification. Available at www.niwa.co.nz/ ncwr/rec/

Moore RD, Griffiths RA, Román A (2004) Distribution of the Mallorcan toad (Alytes muletensis) in relation to landscape topography and introduced predators. Biol Conserv 116:327-332

Nájera-Hillman E, King P, Alfaro CA, Breen BB (2009a) Effect of pest-management operations on the abundance and size-frequency distribution of the New Zealand endemic frog Leiopelma hochstetteri. NZ J Zool 36:389-400

Nájera-Hillman E, Alfaro CA, Breen BB, O'Shea S (2009b) Characterisation $\left(\delta^{13} \mathrm{C}\right.$ and $\delta^{15} \mathrm{~N}$ isotopes) of the food webs in a New Zealand stream in the Waitakere Ranges, with emphasis on the trophic level of the endemic frog Leiopelma hochstetteri. NZ J Zool 36:165-176

Odum EP (1992) Great ideas in ecology for the 1990s. Bioscience 42:542-545

Payton IJ, Allen RB, Knowlton JE (1984) A post-fire succession in the northern Urewera forests, North Island, New Zealand. NZ J Bot 22:207-222

Pellet J, Schmidt BR (2005) Monitoring distributions using call surveys: estimating site occupancy, detection probabilities and inferring absence. Biol Conserv 123:27-35

Platt GC (2002) The place of kauri (Agathis australis) in the six-stage sequential order of forest succession/pregression. NZ Gard J 5:12-19

Editorial responsibility: Michael Mahony,

Callaghan, New South Wales, Australia
Robb J (1980) New Zealand amphibians and reptiles. William Collins Publishers, Auckland

> Roelants K, Bossuyt F (2005) Archaebatachian paraphyly and pangaean diversification of crown-group frogs. Syst Biol 54:111-126

Royle JA, Nichols JD (2003) Estimating abundance from repeated presence-absence data or point counts. Ecology 84:777-790

Sherman PW, Runge MC (2002) Demography of population collapse: the northern Idaho ground squirrel (Spermophilus brunneus brunneus). Ecology 83:2816-2831

Strahler AN, (1957) Quantitative analysis of watershed geomorphology. Trans Geophys Union 8(6):913-920

> Sugimoto S, Nakamura F, Ito A (1997) Heat budget and statistical analysis of the relationship between stream temperature and riparian forest in the Toikanbetsu river basin, northern Japan. J For Res 2:103-107

Tessier C, Slaven D, Green DM (1991) Population density and daily movement patterns of Hochstetter's frogs, Leiopelma hochstetteri, in a New Zealand mountain stream. J Herpetol 25:213-214

Towns DR, Daugherty CH (1994) Patterns of range contractions and extinctions in the New Zealand herpetofauna following human colonisation. NZ J Zool 21:325-339

Tyre AJ, Tenhumberg B, Field SA, Niejalke D, Parris K, Possingham HP (2003) Improving precision and reducing bias in biological surveys by estimating false negative error rates in presence-absence data. Ecol Appl 13:1790-1801

Wells KD (2007) The ecology and behaviour of amphibians. The University of Chicago Press, Chicago, IL

Whitaker AH, Alspach PA (1999) Monitoring of Hochstetter's frog (Leiopelma hochstetteri) populations near Golden Cross Mine, Waitekauri Valley, Coromandel. Science for Conservation 130. Department of Conservation, Wellington

Worthy TH (1987) Paleoecological information concerning members of the frog genus Leiopelma: Leiopelmatidae in New Zealand. J R Soc N Z 17:409-420

Ziegler S (1999) Distribution, abundance and habitat preferences of Hochstetter's frog in the Waitakere Ranges, Auckland. MSc thesis, University of Auckland

Submitted: May 14, 2009; Accepted: August 27, 2009

Proofs received from author(s): October 23, 2009 